\title{
Koncepcja usprawnienia procesu spawania sekcji przestrzennych jednostek wielogabarytowych w stoczni X
}

\author{
The concept of improving the welding process \\ of large-size unit spatial at the shipyard X with welding methods
}

\section{Streszczenie}

Celem artykułu jest przedstawienie koncepcji usprawnienia procesu spawania sekcji przestrzennych w kadłubie statku. Przedmiotem analizy projektu będzie styk międzyblokowy, który pospawany zostanie dwoma różnymi metodami. W artykule przedstawione zostaną rozwiązania techniczne wspomagające procesy spawalnicze oraz pomiary i obliczenia umożliwiające porównanie obu metod spawania.

Słowa kluczowe: technologia spawania; optymalizacja technologii; konstrukcje spawane

\section{Wstęp}

Spawanie jest najbardziej pracochłonnym procesem w budowie kadłuba statku. Brak odpowiedniego zaplecza kadry spawaczy znacznie wydłuża czas wykonania projektu. Wiąże się to często z karami, jakie przedsiębiorstwo musi ponieść za opóźnione terminy wykonania. Aby zminimalizować straty w przedsiębiorstwie, powinno się podjąć analizę usprawnienia dotychczasowych metod spawania w różnych rejonach statku.

Jakość złącza wykonanego w procesie spawania można zazwyczaj ocenić dopiero dobę po jego zakończeniu. W wielu przypadkach, zwłaszcza na zmechanizowanych i zrobotyzowanych stanowiskach spawalniczych, jakość złącza powinna być oceniana w czasie jego wykonywania, bezpośrednio na stanowisku spawalniczym [1].

Rosnące wymagania odnośnie jakości wykonywanych złączy również wpływają na dynamiczny rozwój techniki spawalniczej, która ma gwarantować wysoką jakość otrzymywanych złączy oraz powtarzalność procesu [2].

Jednym z możliwych rozwiązań, które pozwala w zasadniczy sposób usprawnić dotychczasowy system spawania, jest zamiana spawania półautomatycznego na spawanie automatyczne. Dzięki zastosowaniu rozwiązań projektowych przedstawionych $\mathrm{w}$ niniejszym artykule będzie możliwa znacząca poprawa kosztów w Stoczni X.

\section{Koszty związane ze spawaniem sekcji przestrzennych kadłuba statku}

Wpływ na wysokość kosztów spawania ma wiele czynników. Podstawowymi są: metoda spawania, grubość i rodzaj spawanego materiału, zastosowanie materiałów dodatkowych, pozycja spawania, wybór fazowania krawędzi [3].

Koszty spawania dzieli się na: koszty bezpośrednie, w których pod uwagę bierze się m.in.: zużycie materiałów spawalniczych, koszt robocizny, zużycie energii elektrycznej oraz koszty pośrednie (dotyczą np. zarządu, administracji, podatków itp.) [4].
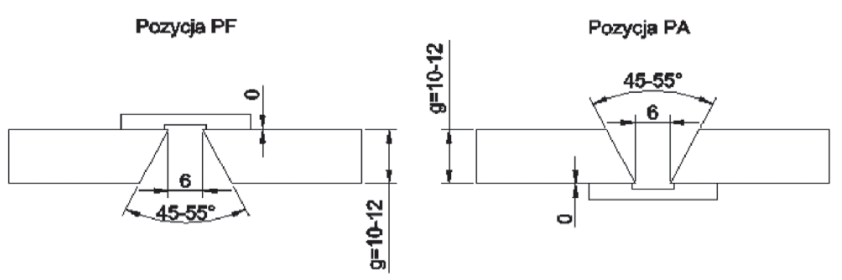

Rys. 1. Podział styku do analizy kosztów spawania przed wprowadzeniem usprawnień, źródło: opracowanie na podstawie materiałów ze stoczni $X$

Fig. 1. The division of welding joint in terms of cost analysis before the improvement introduction, source: based on shipyard product catalogues

Dr inż. Ryszard Bielski; dr inż. Radosław Drozd - Politechnika Gdańska.

Autor korespondencyjny/Corresponding author. rbi@zie.pg.gda.pl 
Koszty spawalniczych materiałów dodatkowych stanowią zużyte druty elektrodowe, gazy osłonowe oraz podkładki technologiczne.

Do kosztów robocizny zalicza się czas potrzebny do wyspawania złącza, który jest określony na podstawie pomiarów lub z odczytów zawartych w normatywach technologicznych.

Koszty energii elektrycznej szacuje się na podstawie mocy elektrycznej zależnej od wykonywanych prac spawalniczych oraz od rodzaju urządzenia. Z urządzeniami związane są koszty amortyzacji oraz remontów.

Analiza kosztów przykładowego procesu spawalniczego obejmuje styk poszycia zewnętrznego Bloku I (ładownia i rufa statku) z Blokiem II (siłownia i dziób statku).

Styk poszycia, przed wprowadzeniem usprawnień, jest spawany w pozycji (PA) oraz pionowej z dołu do góry (PF) 30 [6]. Wymienione pozycje spawania obrazuje rysunek 1.

Ze względu na występowanie trzech różnych grubości blach w analizowanym styku blokowym autorzy podzielili je na części: nr 1, nr 2, nr 3 [7]. Obliczenia poszczególnych odcinków spoiny dotyczą lewej i prawej burty (rys. 2).

\section{Projekt zastosowania zautomatyzowanej metody spawania styków blokowych w kadłubie statku}

Przedstawienie metody spawania proponowanej w projekcie

Proponowany projekt polega na zastosowaniu automatycznego spawania metodą 136. Metoda ta będzie umożliwiała spawaczowi szybkie i dokładne wykonanie spoin o różnych długościach na powierzchniach płaskich oraz zakrzywionych. Zastosowanie w projekcie nowoczesnego urządzenia pozwoli na wykonanie spawania złączy doczołowych, jak również pachwinowych.

Analizę kosztów przeprowadzono na przykładzie wielofunkcyjnego systemu Railtrac FWR 1000 (rys. 3), który będzie wykorzystywany w przedsiębiorstwie przy spawaniu i cięciu [5].

Podzespoły i elementy wskazanego urządzenia będą wykonane dla celów badawczych ze specjalnych materiałów, które pozwalają na ekstremalne warunki pracy. Obudowa

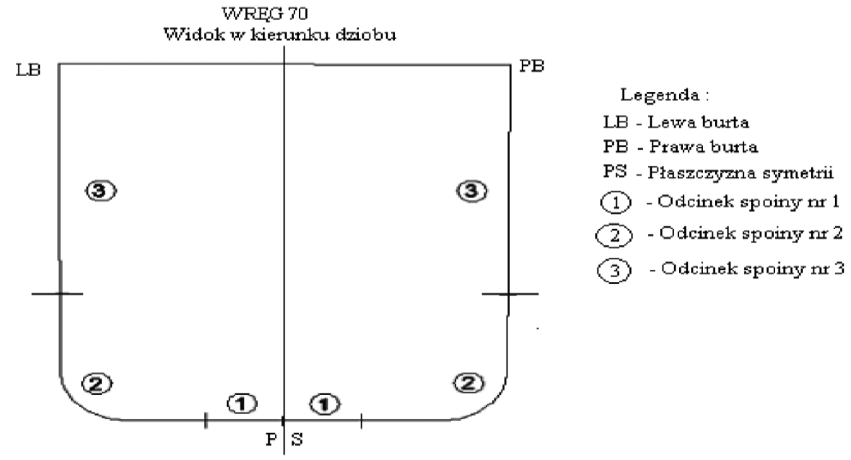

Rys. 2. Podział styku do analizy kosztów spawania, Źródło: opracowanie na podstawie materiałów ze stoczni $X$

Fig. 2. The division of welding joint in terms of cost analysis, Source: Based on shipyard product catalogues

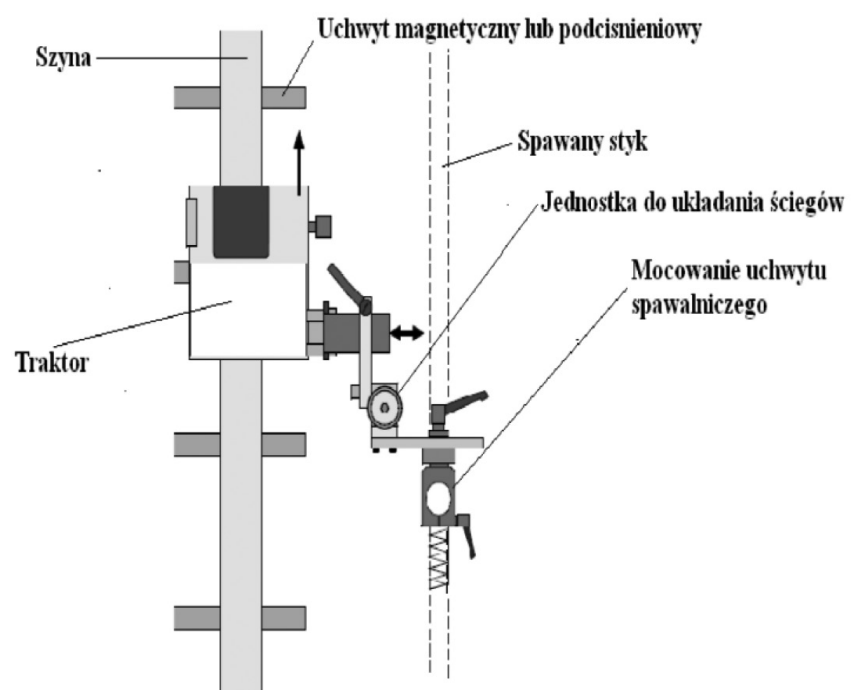

Rys. 3. Schemat urządzenia Railtrac FWR 1000 firmy ESAB, źródło: opracowanie na podstawie katalogów produktów stoczni $X$ oraz firmy ESAB

Fig. 3. Scheme of a device Railtrac FWR 1000 ESAB company, source: Based on shipyard product catalogues and ESAB company

Tablica I. Wpływ wybranych parametrów procesu na geometrię modeli 3D (fragment) $[3,4]$

Table I. The impact of the selected process parameters on the geometry of 3D models (fragment)

\begin{tabular}{|c|c|c|c|c|c|c|c|}
\hline $\begin{array}{l}\text { Numery } \\
\text { odcinków } \\
\text { spoiny }\end{array}$ & $\begin{array}{c}\text { Grubość } \\
\text { blachy }\end{array}$ & $\begin{array}{c}\text { Warstwa } \\
\text { ściegu }\end{array}$ & $\begin{array}{l}\text { Zakładana } \\
\text { prędkość } \\
\text { spawania }\end{array}$ & $\begin{array}{c}\text { Prędkość } \\
\text { spawania } \\
\text { jednego metra } \\
\text { spoiny }\end{array}$ & $\begin{array}{l}\text { Długość } \\
\text { odcinka }\end{array}$ & $\begin{array}{l}\text { Czas } 1 \text { metra * } \\
\text { długość } \\
\text { odcinka styku }\end{array}$ & $\begin{array}{c}\text { Czas } \\
\text { w minutach }\end{array}$ \\
\hline 1 & $12 \mathrm{~mm}$ & 1 & $15 \mathrm{~cm} / 1 \mathrm{~min}$ & $6 \mathrm{~min} .40$ sek. & $6,3 \mathrm{~m}$ & $6,67 \times 6,3$ & 42,02 \\
\hline 1 & $12 \mathrm{~mm}$ & 2 & $20 \mathrm{~cm} / 1 \mathrm{~min}$ & $5 \mathrm{~min}$ & $6,3 \mathrm{~m}$ & $5 \times 6,3$ & 31,50 \\
\hline 1 & $12 \mathrm{~mm}$ & 3 & $20 \mathrm{~cm} / 1 \mathrm{~min}$ & $5 \mathrm{~min}$ & $6,3 \mathrm{~m}$ & $5 \times 6,3$ & 31,50 \\
\hline 1 & $12 \mathrm{~mm}$ & 4 & $20 \mathrm{~cm} / 1 \mathrm{~min}$ & $5 \mathrm{~min}$ & $6,3 \mathrm{~m}$ & $5 \times 6,3$ & 31,50 \\
\hline 2 & $10 \mathrm{~mm}$ & 1 & $20 \mathrm{~cm} / 1 \mathrm{~min}$ & $5 \mathrm{~min}$ & $11,56 \mathrm{~m}$ & $5 \times 11,56$ & 57,80 \\
\hline 2 & $10 \mathrm{~mm}$ & 2 & $30 \mathrm{~cm} / 1 \mathrm{~min}$ & $3 \mathrm{~min} .20$ sek. & $11,56 \mathrm{~m}$ & $3,33 \times 11,56$ & 38,49 \\
\hline 2 & $10 \mathrm{~mm}$ & 3 & $30 \mathrm{~cm} / 1 \mathrm{~min}$ & $3 \mathrm{~min} .20$ sek. & $11,56 \mathrm{~m}$ & $3,33 \times 11,56$ & 38,49 \\
\hline 3 & $11 \mathrm{~mm}$ & 1 & $20 \mathrm{~cm} / 1 \mathrm{~min}$ & $5 \mathrm{~min}$. & $18,54 \mathrm{~m}$ & $5 \times 18,54$ & 92,70 \\
\hline 3 & 11 mm & 2 & $30 \mathrm{~cm} / 1 \mathrm{~min}$ & $3 \mathrm{~min} .20$ sek. & $18,54 \mathrm{~m}$ & $3,33 \times 18,54$ & 61,74 \\
\hline 3 & $11 \mathrm{~mm}$ & 3 & $30 \mathrm{~cm} / 1 \mathrm{~min}$ & $3 \mathrm{~min} .20$ sek. & $18,54 \mathrm{~m}$ & $3,33 \times 18,54$ & 61,74 \\
\hline & & & & \multicolumn{3}{|r|}{$\Sigma$} & 418,47 \\
\hline
\end{tabular}


urządzenia będzie chroniła je przed odpryskami podczas spawania oraz warunkami atmosferycznymi.

W analizowanym projekcie traktor podczas procesu spawania będzie poruszał się po giętkiej aluminiowej szynie, która dopasowana będzie do kształtu powierzchni elementu spawanego. Szyna ta będzie zamontowana za pomocą magnesów lub podciśnieniowo. Kierunek spawania i parametry będą zależne od wprowadzonego programu do sterownika urządzenia. Operator urządzenia będzie korzystał z pilota nadzorującego i korygującego działanie maszyny.

Analiza kosztów wprowadzenia nowego systemu spawania

Analiza kosztów nowej metody spawania obejmuje sam styk, dlatego omówione zostaną tylko i wyłącznie różnice wynikające ze zmiany sposobu spawania.

Styk blokowy będzie spawany w pozycji pułapowej (PE) oraz pionowej z dołu do góry (PF) [6].

Waga spoiny wynosi $4,01 \mathrm{~kg}$. Ze względu na tę samą metodę spawania (136) zużycie drutu potrzebnego do pospawania jest również takie same i wynosi 3,5 kg. Ilość podkładek ceramicznych wynosi 61 sztuk. Ze względu na automatyzację posuwu palnika półautomatu znacznie skraca się czas spawania, który z kolei ma wpływ na zużycie gazów (tabl. I) [8].

Ilość zużycia gazu oblicza się mnożąc sumę czasu spawania z przyjętym wskaźnikiem zużycia I/m, tj. $487,47 \mathrm{~min} \times 18 \mathrm{I} / \mathrm{min}=8774,46$ litrów gazu

$$
8774,46: 1000=8,8 \mathrm{~m}^{3}
$$

Nowe koszty materiałów dodatkowych użytych do spawania styku Bloków I i II (tabl. II).

Tablica II. Koszty materiałów dodatkowych po wprowadzeniu usprawnienia

Table II. Costs of additional materials after the improvement introduction

\begin{tabular}{|c|c|c|c|c|}
\hline $\begin{array}{c}\text { Koszty } \\
\text { materiału } \\
\text { dodatkowego }\end{array}$ & $\mathrm{JM}$ & $\begin{array}{c}\text { Potrzeb- } \\
\text { na ilość }\end{array}$ & $\begin{array}{c}\text { Średni } \\
\text { koszt } \\
\text { jednost- } \\
\text { kowy }\end{array}$ & $\begin{array}{c}\text { Średni } \\
\text { koszt } \\
\text { całkowity }\end{array}$ \\
\hline $\begin{array}{c}\text { Drut spawalniczy OK. } \\
\text { TUBROD 15.14 1,2 }\end{array}$ & $\mathrm{kg}$ & 3,5 & $7,10 \mathrm{zł}$ & $24,85 \mathrm{zł}$ \\
\hline $\begin{array}{c}\text { Podkładka } \\
\text { ceramiczna }\end{array}$ & $\mathrm{szt}$ & 61 & $1,90 \mathrm{zł}$ & $115,90 \mathrm{zł}$ \\
\hline Mieszanka AR CO $\mathrm{CO}^{2}$ & $\mathrm{~m}^{3}$ & 8,8 & $7,90 \mathrm{zł}$ & $69,52 \mathrm{zł}$ \\
\hline
\end{tabular}

Źródło: Opracowanie na podstawie katalogów produktów stoczni $X$ oraz firmy ESAB

Source: Based on shipyard product catalogues and ESAB company

Tablica III. Koszty energii elektrycznej po wprowadzeniu usprawnienia

Table III. The cost of electricity after the improvement introduction

\begin{tabular}{|l|c|}
\hline $\begin{array}{l}\text { Przyjęte parametry spawania } \\
\text { wg wewnętrznej procedury } \\
\text { spawania (WPS) }\end{array}$ & \\
\hline Natężenie prądu & $180 \mathrm{~A}$ \\
\hline Napięcie prądu & $28 \mathrm{~V}$ \\
\hline Czas spawania & $8,12 \mathrm{~h}$ \\
\hline Średni koszt energii za $1 \mathrm{kwh}$ & $0,62 \mathrm{zł}$ \\
\hline $\begin{array}{l}\text { Zużycie prądu = natężenie x } \\
\text { napięcie x czas }\end{array}$ & $\begin{array}{c}180 \mathrm{~A} \times 28 \mathrm{~V} \times 8,12 \mathrm{~h}= \\
40,924 \mathrm{kWh}\end{array}$ \\
\hline Zużycie prądu & $\begin{array}{c}180 \mathrm{~A} \times 28 \mathrm{~V} \times 8,12 \mathrm{~h}= \\
40,924 \mathrm{kWh}\end{array}$ \\
\hline $\begin{array}{l}\text { Źródło: Opracowanie na podstawie katalogów produktów stoczni X oraz firmy ESAB } \\
\text { Source: Based on shipyard product catalogues and ESAB company }\end{array}$ \\
\hline
\end{tabular}

Zużycie prądu oblicza się według parametrów oraz czasu spawania (tabl. III).

Urządzenie spawalnicze wykorzystane do usprawnienia prac spawalniczych - średni koszt urządzenia: 66 424,63 zł.

Do spawania styku skierowany jest tylko operator maszyny. Koszty związane z operatorem urządzenia zawarte zostały w tablicy IV.

Tablica IV. Koszty robocizny operatora po wprowadzeniu usprawnienia

Table IV. Operator labour costs after the improvement introduction

\begin{tabular}{|l|c|}
\hline Koszty robocizny operatora & $3540 \mathrm{zt} /$ miesiąc \\
\hline Średnie wynagrodzenie operatora & $3540 \mathrm{zł}: 160 \mathrm{~h}=22,10 \mathrm{zł}$ \\
\hline $\begin{array}{l}\text { Stawka wynagrodzenia za } \\
\text { godzinę pracy }\end{array}$ & $8,12 \mathrm{~h}$ \\
\hline Czas pracy spawacza & $8,12 \mathrm{~h} * 22,10 \mathrm{zł}=179,45 \mathrm{zł}$ \\
\hline Wynagrodzenie & $\begin{array}{l}|c| \\
\text { Źródło: Opracowanie na podstawie katalogów produktów stoczni } X \text { oraz firmy ESAB } \\
\text { Source: Based on shipyard product catalogues and ESAB company }\end{array}$ \\
\hline
\end{tabular}

Amortyzacja urządzeń spawalniczych wynosi $18 \%$. Obliczenia amortyzacji nowego urządzenia zawarte są w tablicy $\mathrm{V}$.

Tablica V. Obliczenia amortyzacji urządzenia do automatyzacji, po wprowadzeniu usprawnienia

Table V. Device depreciation calculations for the purposes of automation after the improvement introduction

\begin{tabular}{|c|c|}
\hline Cena urządzenia & $\begin{array}{c}13450 \mathrm{zł}+66424,63 \mathrm{zł} \\
=79874,63 \mathrm{zł}\end{array}$ \\
\hline Stopa amortyzacji & $18 \%$ \\
\hline $\begin{array}{l}\text { Nominalny czas pracy w ciągu } \\
\text { roku }\end{array}$ & $2000 \mathrm{~h}$ \\
\hline Całkowity czas spawania & $8,12 \mathrm{~h}$ \\
\hline $\begin{array}{l}\text { Cena urządzenia x stopa } \\
\text { amortyzacji }\end{array}$ & $\begin{array}{c}79874,63 \text { zł x } 18 \%=14377,43 \\
\text { zł koszt na rok) }\end{array}$ \\
\hline $\begin{array}{l}\text { Koszt na rok: nominalny czas } \\
\text { pracy w ciągu roku }\end{array}$ & $\begin{array}{c}\text { 14377,43 zł: } 2000 \mathrm{~h}=7,18 \mathrm{zł} \\
\text { (koszt jednej godziny) }\end{array}$ \\
\hline $\begin{array}{l}\text { Całkowity koszt spawania } \\
\text { x koszt jednej godziny }\end{array}$ & $\begin{array}{l}7,18 \mathrm{zł} \text { x 8,12 h=58,30 zł } \\
\quad(\text { koszt amortyzacji) }\end{array}$ \\
\hline
\end{tabular}

Do obliczanie kosztów remontów urządzeń, autorzy przyjęli szacunkowo, że koszt ten stanowi 9\% kosztów amortyzacji.

Koszt amortyzacji x 9\% $=58,30 \times 0,09=5,25$ zł. Koszt remontów wynosi 5,25 zł.

\section{Porównanie metod spawania sekcji przestrzennych}

Aby zbadać wpływ działania projektu usprawnienia spawania sekcji przestrzennych autorzy, dokonali porównania "starej" obecnej metody spawania stosowanej w stoczni z proponowaną nową. Do porównania posłużą wcześniej obliczone i opracowane dane dotyczące kosztów jednej i drugiej metody.

Zużycie gazów i energii elektrycznej zależy od: czasu spawania, wydatku gazu oraz parametrów spawania. 
Porównanie czasów spawania oraz zużycie gazów i energii elektrycznej zawarte jest w tablicy VI.

Tablica VI. Obliczenia amortyzacji urządzenia do automatyzacji, po wprowadzeniu usprawnienia

Table VI. Device depreciation calculations for the purposes of automation after the improvement introduction

\begin{tabular}{|l|c|c|}
\hline & Metoda 1 & Metoda 2 \\
\hline Czas spawania & $15,3 \mathrm{~h}$ & $8,12 \mathrm{~h}$ \\
\hline $\begin{array}{l}\text { Zużycie energii } \\
\text { elektrycznej }\end{array}$ & $67,62 \mathrm{kWh}$ & $40,92 \mathrm{kWh}$ \\
\hline $\begin{array}{l}\text { Zużycie gazów } \\
\text { osłonowych do } \\
\text { spawania }\end{array}$ & $16,5 \mathrm{~m}^{3}$ & $8,8 \mathrm{~m}^{3}$ \\
\hline $\begin{array}{l}\text { Źródło: Opracowanie na podstawie katalogów produktów stoczni oraz firmy ESAB } \\
\text { Source: Based on shipyard product catalogues and ESAB company }\end{array}$ \\
\hline
\end{tabular}

Usprawnienie metody spawania wpłynęło znacznie na obniżenie kosztów.

Porównanie obliczonych kosztów bezpośrednich zawarte jest w tablicy VII.
Z przeprowadzonej analizy wdrożenia nowej metody spawania wynika, że do poniesionych bezpośrednich kosztów związanych ze spawaniem badanego styku między blokowego zostały uwzględnione te same rodzaje kosztów, tj. koszt materiałów dodatkowych, koszt zużycia energii elektrycznej, koszt robocizny, koszt amortyzacji i remontów urządzenia.

Pierwszym analizowanym kosztem były dodatkowe materiały spawalnicze, które obliczone zostały na podstawie podstawowych danych do analizy kosztów nowego rozwiązania. Zestawienie obliczonych kosztów zawarte jest w tablicy I i wynosi 210,27 zł.

Koszt zużycia energii elektrycznej potrzebnej do zasilenia urządzeń spawalniczych oszacowany został w tablicy III i wynosi 25,37 zł.

Następny obliczany koszt dotyczył wynagrodzenia pracowników za wykonanie pracy, który zawiera tablica IV i wynosi 179,45 zł.

Kolejnymi kosztami analizowanymi były opłaty związane z amortyzacją i remontami urządzenia wykorzystywanego do procesu spawania, które zawarte są w tablicy $V$ i wynoszą 58,30 zł (amortyzacja) oraz 5,25 zł (remonty urządzenia).

Po podsumowaniu wszystkich kosztów bezpośrednich poniesionych $\mathrm{w}$ usprawnionym procesie spawania stwierdzono, że wykonanie badanego odcinka styku międzyblokowego będzie wynosiło 478,64 zł (tabl. VII).

Tablica VII. Zestawienie kosztów bezpośrednich w obu metodach spawania

Table VII. Summary direct costs in both welding methods

\begin{tabular}{|c|c|c|c|}
\hline \multicolumn{2}{|c|}{ Parametry kosztowe procesu } & \multicolumn{2}{|c|}{ Parametry kosztowe procesu } \\
\hline Cena urządzenia (zl) & 13450 & Cena urządzenia (zl) & 66424,63 \\
\hline Cena energii elektrycznej 1 kWh (zl) & 0,62 & Cena energii elektrycznej 1 kWh (zl) & 0,62 \\
\hline Cena drutu proszkowego (zl/kg) & 7,1 & Cena drutu proszkowego $(\mathrm{z} / \mathrm{kg})$ & 7,1 \\
\hline Cena podkładki ceramicznej (zt/szt.) & 1,9 & Cena podkładki ceramicznej (zl/szt.) & 1,9 \\
\hline Cena gazu oslonowego $\left(\mathrm{z} l / \mathrm{m}^{3}\right)$ & 7,9 & Cena gazu osłonowego $\left(\mathrm{zl} / \mathrm{m}^{3}\right)$ & 7,9 \\
\hline Stawka amortyzacyjna (\%) & 18 & Stawka amortyzacyjna (\%) & 18 \\
\hline Nominalny fundusz czasu pracy (h/rok) & 2000 & Nominalny fundusz czasu pracy (h/rok) & 2000 \\
\hline \multicolumn{2}{|c|}{ Poniesione koszty bezpośrednie } & \multicolumn{2}{|c|}{ Poniesione koszty bezpośrednie } \\
\hline Koszt drutu proszkowego (zf) & 24,85 & Koszt drutu proszkowego (zl) & 24,85 \\
\hline Koszt podkladek ceramicznych (zl) & 115,9 & Koszt podkładek ceramicznych (zl) & 115,9 \\
\hline Koszt gazu osłonowego (zl) & 130,35 & Koszt gazu osłonowego (zl) & 69,52 \\
\hline Koszt robocizny (zh) & 429,93 & Koszt robocizny (zi) & 179,45 \\
\hline Koszt energii elektrycznej (zd) & 41,93 & Koszt energii elektrycznej (zl) & 25,37 \\
\hline Koszt amortyzacji urządzenia (zl) & 18,75 & Koszt amortyzacji urządzenia (zl) & 58,3 \\
\hline Koszt remontów urządzenia (zl) & 1,7 & Koszt remontów urządzenia (d) & 5,25 \\
\hline Koszt bezpośredni wykonania spoiny (zl) & 763,41 & Koszt bezpośredni wykonania spoiny (zl) & 478,64 \\
\hline
\end{tabular}

\section{Podsumowanie}

Analizując koszty oraz czasy przedstawionych w artykule metod spawania sekcji przestrzennych (aktualnej oraz proponowanej) autorzy zauważyli:

- po wprowadzeniu projektu usprawniającego koszt spawania analizowanego styku blokowego będzie o $37 \%$ niższy niż przy stosowaniu metody konwencjonalnej

- zmniejszy się czas spawania o ok. 7 godzin, co wpłynie na obniżenie kosztów zużycia gazu osłonowego (60,83 zł), kosztów zużycia energii elektrycznej (16,56 zł) oraz kosztów robocizny $(250,48$ zł). 
Ze względu na cenę urządzenia zwiększy się koszt amortyzacji o 39,55 zł oraz koszt remontów urządzenia o 3,55 zł.

Po przeanalizowaniu wszystkich kosztów bezpośrednich w proponowanym projekcie usprawniającym nowa metoda spawania pozwoli na zaoszczędzenie w stoczni 284,77 zł.

Zakładając 7 h pracy urządzenia dziennie, inwestycja zwróci się po 234 dniach.

Wdrożenie takiego urządzenia w stoczni pozwoli uzyskać wzrost wydajności poprzez skrócenie czasu spawania i uniknięcie wysokich kar pieniężnych za opóźnienia. Poprzez zautomatyzowanie procesu spawania styków poszyciowych możliwe jest uzyskanie powtarzalności wykonania spoiny oraz polepszenie jej jakości.

\section{Literatura}

[1] K. Luksa, J. Fitrzyk, E. Szpakowski: Analiza parametrów spawania GMA metodą wykrywania zakłóceń procesu spawania, Przegląd spawalnictwa, vol. 84, nr 11, s.29-34, 2012.

[2] M. Gucwa, R. Bęczkowski, M. Stefański: Spawanie orbitalne wężownic ze stali VM12-SHC, Przegląd spawalnictwa, vol. 87, nr 10, s.120-123, 2015.

[3] K. Dajczak: Przemysł stoczniowy w Polsce i na świecie, Politechnika Krakowska, Kraków, s. 11-12, 2008.

[4] D. Dębski: Ekonomika i organizacja przedsiębiorstwa cz. 1, WSiP, Warszawa, s.35-36, 2006

[5] T. Grochecki T: Usprawnienie procesu spawania, WSB Gdańsk, Gdańsk, s.46-50, 2016.

[6] PN-EN ISO 6947:2011, Spawanie i procesy pokrewne -- Pozycje spawania.

[7] Shipbuilding and Repair Quality Standard, Table 8.2 - Typical Butt Weld Plate Edge Preparation (Manual Welding and Semi-Automatic Welding) for Reference, No.47 pp 24.

[8] PN-EN ISO 14175:2009, Materiały dodatkowe do spawania -- Gazy i mieszaniny gazów do spawania i procesów pokrewnych. 